\title{
A narrative review of binge eating disorder in adolescence: prevalence, impact, and psychological treatment strategies
}

This article was published in the following Dove Press journal:

Adolescent Health, Medicine and Therapeutics

\section{Eleonora Marzilli' \\ Luca Cerniglia ${ }^{2}$ \\ Silvia Cimino'}

'Department of Dynamic and Clinical Psychology, Psychology and Medicine Faculty, Sapienza - University of Rome, ${ }^{2}$ Department of Psychology, Psychology Faculty, International Telematic University Uninettuno, Rome, Italy
Correspondence: Luca Cerniglia Department of Psychology, Psychology Faculty, International Telematic University Uninettuno, Corso Vittorio Emanuele II, 39 - 00I00, Rome, Italy $\mathrm{Tel}+390669201$

Email l.cerniglia@uninettunouniverisity.net

\begin{abstract}
Binge eating disorder (BED) represents one of the most problematic clinical conditions among youths. Research has shown that the developmental stage of adolescence is a critical stage for the onset of eating disorders (EDs), with a peak prevalence of BED at the age of 16-17 years. Several studies among adults with BED have underlined that it is associated with a broad spectrum of negative consequences, including higher concern about shape and weight, difficulties in social functioning, and emotional-behavioral problems. This review aimed to examine studies focused on the prevalence of BED in the adolescent population, its impact in terms of physical, social, and psychological outcomes, and possible strategies of psychological intervention. The review of international literature was made on paper material and electronic databases ProQuest, PsycArticles, and PsycInfo, and the Scopus index were used to verify the scientific relevance of the papers. Epidemiological research that examined the prevalence of BED in adolescent samples in accordance with Diagnostic and Statistical Manual of Mental Disorders, 4th Edition showed a prevalence ranging from $1 \%$ to $4 \%$. More recently, only a few studies have investigated the prevalence of BED, in accordance with the Diagnostic and Statistical Manual of Disorders, Fifth Edition criteria, reporting a prevalence of $\sim 1 \%-5 \%$. Studies that focused on the possible impact that BED may have on physical, psychological, and social functioning showed that adolescents with BED have an increased risk of developing various adverse consequences, including obesity, social problems, substance use, suicidality, and other psychological difficulties, especially in the internalizing area. Despite the evidence, to date, reviews on possible and effective psychological treatment for BED among young population are rare and focused primarily on adolescent females. Keywords: binge eating, adolescence, prevalence, impact, treatment
\end{abstract}

\section{Introduction}

Binge eating disorder (BED) is an empirically validated eating disorder (ED), ${ }^{1-3}$ introduced in May 2013 in the Diagnostic and Statistical Manual of Disorders, Fifth Edition (DSM-5). ${ }^{4}$ BED is characterized by recurrent episodes of unusually large amount of food intake without compensatory behaviors, and it is associated with subjective experience of feeling of loss of control (LOC) and marked distress. ${ }^{5-8}$ Originally, BED was introduced in the appendix of the Diagnostic and Statistical Manual of Disorders, 4th Edition, Text Revision (DSM-IV-TR), ${ }^{9}$ as a subcategory of Eating Disorders Not Otherwise Specified (EDNOS). Criteria required binge eating episodes at least twice per week for 6 months, but the new DSM-5 changed this threshold to at least once a week for 3 months. ${ }^{10}$ Generally, binge eating episodes are preceded by intense feeling of craving, ${ }^{11}$ and several researchers have suggested that binge eating may serve as a maladaptive strategy for coping with negative mood states. ${ }^{12-16}$ 
BED is the most prevalent form of ED and one of the primary chronic illnesses among adolescents. ${ }^{17}$ Adolescence is a transitional developmental stage characterized by rapid and deep physical, psychological, and neural development changes, and it represents a critical period for the onset of EDs, including BED. ${ }^{18-21}$ During this period, youths experience fast neurobiological and body modifications, which may be accompanied by increased concern and attention for body size and shape, ${ }^{22-24}$ as the awareness of societal pressures for thinness and relationships with peers becomes increasingly important, leading to a higher concern about peer acceptance.$^{25-27}$ For these reasons, although EDs can affect individuals of all ages, adolescence represents a peak lifetime period of increased vulnerability for the onset of EDs. ${ }^{28,29} \mathrm{In}$ particular, an increased prevalence of ED symptoms among youths aged $14-16$ years has been evidenced, ${ }^{30}$ with two peaks of onset of BED, the first immediately after puberty, at a mean age of 14 years, ${ }^{31}$ and the second in late adolescence (19-24 years), between 18 and 20 years. ${ }^{32}$

In the general population, international research has reported that $26 \%$ of female and $13 \%$ of male adolescents have experienced an episode of binge eating at least once in the last 12 months $^{33}$ and that subclinical symptoms of BED can be associated with a higher risk of developing BED $^{34}$ and/or other adverse outcomes, including lower self-esteem and higher body dissatisfaction. ${ }^{35}$

It is noteworthy that binge eating episodes in adolescence could be difficult to differentiate from nonclinical behaviors, as youths could indulge in large food consumption due the developmentally specific growth spurts. ${ }^{36}$ Consequently, it has been suggested that the criterion of LOC eating is the most salient marker of BED in this developmental phase, especially for early adolescents. ${ }^{37}$ Furthermore, adolescents may also show less frequent episodes of binge eating than it is necessary to pose a diagnosis of BED according to the Diagnostic and Statistical Manual of Mental Disorders. ${ }^{18,38,39}$ For these reasons, it is important for clinicians to consider subthreshold binge eating disorder (SBED) in adolescents. ${ }^{32,34,37,40}$

It has also been evidenced that female adolescents frequently report less overeating than male adolescents, ${ }^{41}$ but more severe indicators of loss of control, ${ }^{10,42}$ and distress during binge eating episodes..$^{10,41}$ Moreover, several studies among adults with BED have shown that this ED is associated with various adverse consequences, including higher distress and concern about shape and weight, ${ }^{43}$ social impairment, ${ }^{8,44}$ and both clinical and subclinical forms of psychological difficulties, especially anxiety and depressive symptoms. ${ }^{7}$

Based on these theoretical and empirical premises, the aim of this narrative review was to examine the current knowledge ${ }^{45}$ of the prevalence of BED in adolescent population, outcomes associated in terms of physical, social, and psychological consequences, and possible psychological strategies of intervention.

\section{Research methods}

The methodological approach adopted in this paper consists of a narrative review, ${ }^{45,46}$ an interpretive-qualitative form of research that, when include some features of a systemic methodology, ${ }^{47}$ can allow synthesizing the findings of literature about a specific theme and improve our knowledge on the topic. ${ }^{48}$ Specifically, our methodological research (Table 1) was inspired by the four steps provided by Egger et $\mathrm{al}^{49}$ as follows: 1) formation of a working group, composed of three operators expert in BEDs; one of them has acted as a methodological operator and the other two as clinical operators; 2) formulation of the review questions on the basis of the state of the art of BED in adolescent population (in terms of its prevalence, impact, and possible psychological treatment strategies), as made in the abstract; 3) identification of relevant studies: the review of international literature was performed through an extensive search on paper materials in university libraries and through electronic databases such as ProQuest, PsycArticles, and PsycInfo and indexing papers published from January 2007 to June 2017, together with the use of Scopus index to verify the scientific relevance of papers. First, in order to examine the prevalence rates of binge eating in adolescent population, we were specifically interested in articles that reported the prevalence of both BED and SBED, in accordance with DSM-IV and DSM-5 criteria, and assessed diagnoses with self-report questionnaires and/ or interview instruments. Despite self-report measurements have methodological limitations compared with interviewbased assessments, we also included studies using report data to classify diagnoses, because epidemiological research of BED in adolescence is still scarce, and these studies may provide important preliminary data for future studies. This research was performed by using relevant combined keywords such as "binge eating disorder," "BED," "subthreshold BED," "adolescent," "youth," "prevalence," and "epidemiology."

Second, to explore the possible impact of BED on adolescents' health and mental health, we searched for studies presenting physical, social, and psychological outcomes in female and male adolescents with BED and SBED, using the following combined search terms: "adolescence," "binge eating," "subthreshold BED," "outcomes," "long-term effects," "impact," "correlates," and "consequences."

Finally, to examine the research focused on possible psychological treatment strategies, we used the keyword 
Table I Summary of methodology

\begin{tabular}{|c|c|c|}
\hline Step & General activities & Specific activities \\
\hline I & Formation of a working group & $\begin{array}{l}\text { Three psychologist experts in binge eating disorder: } \\
\text { I. One as a methodological operator } \\
\text { 2. Two as clinical operators }\end{array}$ \\
\hline 2 & $\begin{array}{l}\text { Formulation of the review } \\
\text { questions }\end{array}$ & $\begin{array}{l}\text { Evaluation of the state of the art on the prevalence of BED in adolescence, its impact, and its } \\
\text { possible psychological treatment strategies }\end{array}$ \\
\hline \multirow[t]{5}{*}{3} & $\begin{array}{l}\text { Identification of relevant studies } \\
\text { on ProQuest, PsycArticles, and }\end{array}$ & $\begin{array}{l}\text { I. Identification of the keywords on the basis of the field of interest of the papers to be searched, } \\
\text { grouped in inverted commas (“...”) and used separately or combined }\end{array}$ \\
\hline & Psyclnfo & 2. Use of the Boolean AND operator, in order to establish a logical relationship among concepts \\
\hline & & 3. Research modalities: advanced search \\
\hline & & 4. Limits: papers published in the last 10 years; languages: English; type of paper: peer-review \\
\hline & & $\begin{array}{l}\text { 5. Manual search through the reference lists of articles, using the Scopus index to verify the } \\
\text { scientific relevance of papers }\end{array}$ \\
\hline 4 & $\begin{array}{l}\text { Analysis and presentation of the } \\
\text { outcomes }\end{array}$ & $\begin{array}{l}\text { The data extrapolated from revised studies were collocated in tables and presented in the form of } \\
\text { a narrative review }\end{array}$ \\
\hline
\end{tabular}

Note: Our methodological strategy was inspired by four steps proposed by Egger et al. ${ }^{49}$

search function by entering the following terms: "binge eating disorder," "adolescence," "youth," "psychological treatment," "psychotherapy," and "intervention."

Given that the criterion of LOC eating has been suggested to be a more appropriate indicator of binge eating in adolescence with respect to amount of food consumed, ${ }^{37}$ we also included treatment studies specifically focused on the reduction of LOC.

We examined the title and screened abstracts of each identified article using these initial search strategies. Then, we also conducted a hand-search of the reference lists of published articles, and papers were inspected for their relevance in the review. On the basis of the evidence of two peaks of onset for $\mathrm{BED}^{31,32}$ (the first in early adolescence and the second in late adolescence), ${ }^{50}$ we included in this review only articles in which sample of adolescents was aged between 10 and 24 years. Furthermore, we selected only papers in which sample or subsample of adolescents was diagnosed with BED or SBED, in accordance with either DSM-IV or DSM- 5 criteria, or studies that examined binge eating symptoms and/or episodes without compensatory behaviors. Other inclusion criteria were that articles in English language and published in peer-reviewed journals. Thesis dissertations were excluded.

The final step is 4) the analysis and presentation of the outcomes; we identified a total of 25 articles, 00 for prevalence, ${ }^{10,18,39,40,51-53,59-62} 11$ for outcomes, ${ }^{18,39,40,59-61,64-68}$ and 6 for psychological treatment. ${ }^{79-84}$ The data extrapolated from these revised studies were collocated in tables and carried out in the form of a narrative review. Table 1 shows the summary of the methodology used in the review. The flow diagram of the narrative review is shown in Figure 1.

\section{Results \\ Prevalence of BED in adolescence}

Given that BED has only recently been introduced into the psychiatric nomenclature, epidemiological research is very limited, especially for adolescent populations. We found 13 prevalence studies specifically focused on youths, which have used different types of measurements to assess diagnoses (Table 2). Five studies ${ }^{18,40,51-53}$ have examined the prevalence of BED in accordance with Diagnostic and Statistical Manual of Mental Disorders, 4th Edition (DSM-IV) and overall reported a rate of prevalence from $1 \%$ to $4 \%$. For example, a study by Decaluwé and Braet ${ }^{51}$ in a population of obese adolescents, using interview measurements, has reported a rate of $\sim 2 \%$. Two other studies ${ }^{52,53}$ have examined the rate of BED in general adolescent population, but using self-report questionnaires, reporting a slightly lower prevalence of $1.2 \%$, with a higher rate among female adolescents. These studies ${ }^{51,52}$ have also underlined the presence of high percentage of youth who did not meet full-threshold criterion for an ED diagnoses, suggesting limitations of classification systems for epidemiological research among adolescent populations.

Finally, we considered two studies ${ }^{18,40}$ that, using interviewbased assessments, have provided the prevalence rates also for SBED, evidencing a higher prevalence of this form in this phase of development. One study ${ }^{40}$ was focused only on adolescent girls, finding a rate of $1 \%$ for BED and $4.6 \%$ for SBED. The second study ${ }^{18}$ had considered both sexes of adolescent population, reporting a prevalence of $1.6 \%$ for BED and $2.5 \%$ for SBED and evidencing higher rates among girls for SBED also.

Changes to diagnostic criteria from DSM-IV-TR to DSM-5 have allowed reducing the prevalence of EDNOS, ${ }^{54}$ which were $\sim 50 \%$ in clinical samples ${ }^{55,56}$ and $70 \%$ in commu- 


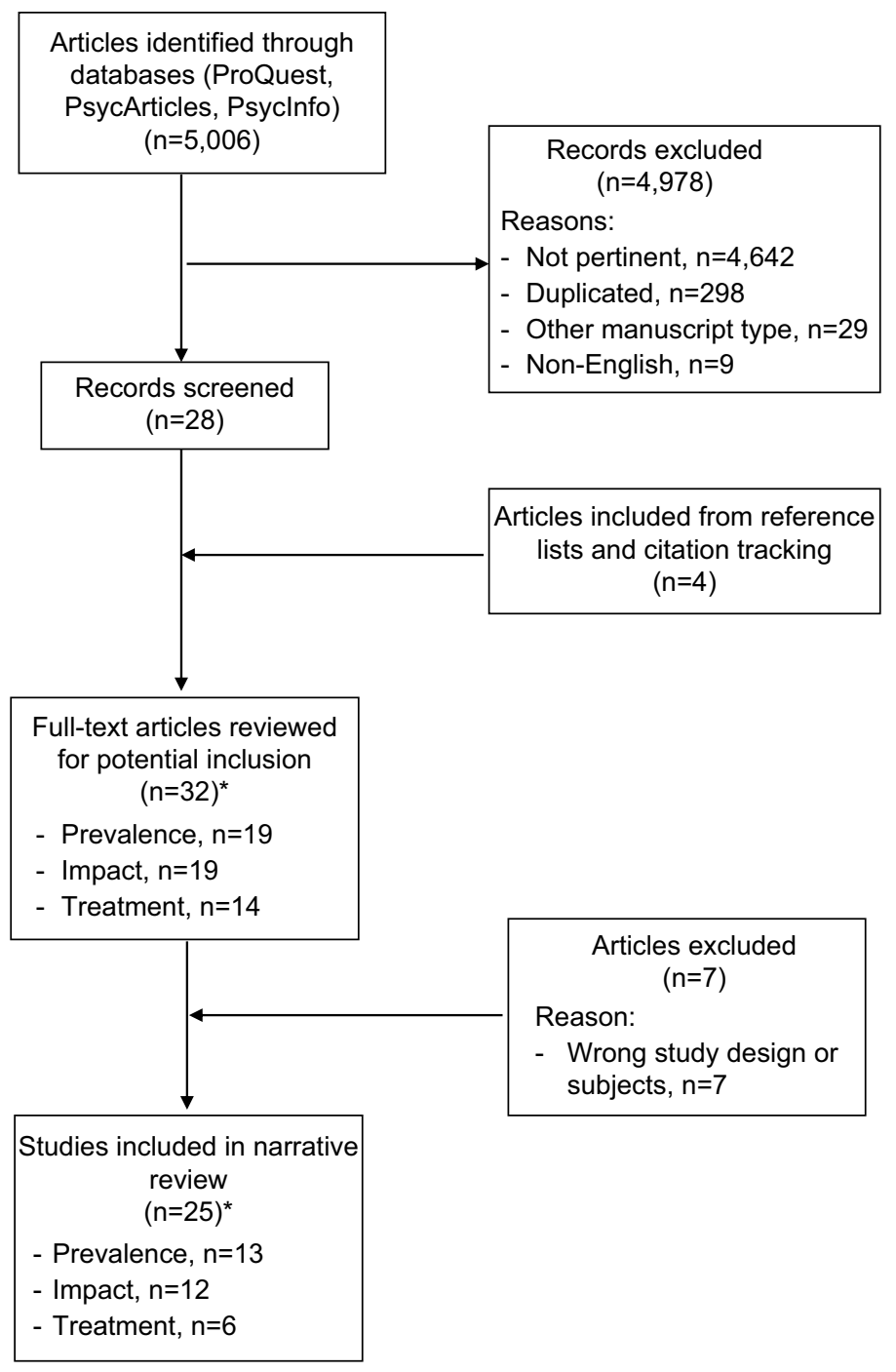

Figure I Flowchart of narrative review.

Note: *Some studies were pertinent to more than one section.

nity samples..$^{57,58}$ To date, the few studies that have examined the prevalence of BED in adolescent samples, in accordance with the recently proposed DSM- 5 criteria, found the prevalence of approximately between $1 \%$ and $5 \%{ }^{10,31,32,39,59-62}$

In particular, we found three studies ${ }^{39,59,61}$ that have longitudinally examined the prevalence of BED in adolescent community samples and that suggested an increase of rate over time. For example, Field et a ${ }^{61}$ found a BED prevalence of $2.5 \%$, which tended to increase during the development, with a peak at 19-22 years of age.

Two other studies ${ }^{39,59}$ have confirmed these findings also among male adolescent samples. Interesting, a study by Allen et $\mathrm{a}^{59}$ has reported that BED prevalence increased over time among female adolescents, starting from $0.7 \%$ in 14-yearold subjects, reaching $1.4 \%$ when they were 17 years, and finally growing up to $4.1 \%$ when they were 20 years old.
In male adolescents, BED prevalence was estimated to be absent $(0 \%)$ at 14 years of age and $1.2 \%$ at 17 years and was decreased to $0.7 \%$ at 20 years, suggesting that adolescent girls have a higher risk of maintaining BED over the course of life. However, another study ${ }^{37}$ found that prevalence of BED generally increased over time among both female and male adolescents, peaked at $\sim 3.3 \%$ at an age of 22 years for girls and $1.2 \%$ at 24 years for boys.

More recently, two cross-sectional studies ${ }^{31,62}$ have reported lower rates of prevalence $(\sim 1.5 \%)$, but among samples of younger adolescents with respects to previous studies in which an increase of prevalence has been evidenced over time.

Finally, we considered three studies ${ }^{10,32,60}$ focused also on the prevalence of SBED. Interestingly, the study by Stice et $\mathrm{al}^{32}$ has examined the prevalence of EDs in the same female 
Table 2 Prevalence of binge eating disorder in adolescent samples

\begin{tabular}{|c|c|c|c|c|c|c|c|c|c|}
\hline \multirow[t]{2}{*}{ Reference } & \multirow[t]{2}{*}{ Age (years) } & \multicolumn{3}{|c|}{ Sample (N) } & \multicolumn{2}{|l|}{ Methods } & \multicolumn{3}{|c|}{ Prevalence (\%) } \\
\hline & & Total & Female & Male & Screening & Criteria & Total & Female & Male \\
\hline Decaluwé and $\mathrm{Braet}^{51}$ & $10-16$ & 196 & 111 & 78 & ChEDE & DSM-IV & I & 1 & 0 \\
\hline Kjelsås et a $\left.\right|^{52}$ & $14-15$ & 1,960 & 1,026 & 934 & SEDs & DSM-IV & 1.2 & 1.5 & 0.9 \\
\hline Ackard et $\mathrm{al}^{53}$ & $13-18$ & 4,746 & 2,373 & 2,273 & EAT & DSM-IV & I.I & 1.9 & 0.3 \\
\hline \multirow[t]{2}{*}{ Stice et $\mathrm{al}^{40}$} & $12-15$ & 496 & 496 & - & EDDI & DSM-IV & $\mathrm{I}^{\mathrm{a}}$ & $\mathrm{I}^{\mathrm{a}}$ & - \\
\hline & 20 & & & & & & $4.6^{\mathrm{b}}$ & $4.6^{\mathrm{b}}$ & \\
\hline \multirow[t]{2}{*}{ Swanson et $\mathrm{al}^{18}$} & $13-18$ & 10,123 & - & - & CIDI & DSM-IV & $1.6^{\mathrm{a}}$ & $2.3^{\mathrm{a}}$ & $0.8^{\mathrm{a}}$ \\
\hline & & & & & & & $2.5^{\mathrm{b}}$ & $2.6^{\mathrm{b}}$ & $2.3^{\mathrm{b}}$ \\
\hline Field et a ${ }^{61}$ & $16-24$ & 8,594 & 8,594 & - & $\begin{array}{l}\text { 2-part } \\
\text { questions }\end{array}$ & DSM-5 & $2-2.5$ & - & - \\
\hline \multirow[t]{3}{*}{ Allen et $\mathrm{al}^{59}$} & $14-17-20$ & $\mathrm{I}, 383$ & 715 & 668 & ChEDE & DSM-5 & 0.9 & 1.8 & 0 \\
\hline & & & & & EDE-Q & & 1.3 & 1.4 & 1.2 \\
\hline & & & & & & & 2.4 & 4.1 & 0.7 \\
\hline Sonneville et al ${ }^{39}$ & $16-24$ & 16,882 & 9,039 & 7,843 & $\begin{array}{l}\text { 2-part } \\
\text { question }\end{array}$ & DSM-5 & $2-3$ & $2.3-3.1$ & $0.3-1$ \\
\hline \multirow[t]{2}{*}{ Crow et a ${ }^{62}$} & $13-18$ & 10,123 & - & - & 2-part & DSM-5 & 1.6 & - & - \\
\hline & & & & & question & & & & \\
\hline \multirow[t]{2}{*}{ Smink et $\mathrm{a}^{31}$} & 19 & $\mathrm{I}, 597$ & 861 & 739 & CIDI & DSM-5 & 1.5 & 2.3 & 0.7 \\
\hline & & & & & EDE & & & & \\
\hline \multirow[t]{2}{*}{ Stice et $\mathrm{al}^{32}$} & $12-15$ & 496 & 496 & - & EDDI & DSM-5 & $3^{\mathrm{a}}$ & $3^{\mathrm{a}}$ & - \\
\hline & 20 & & & & & & $3.6^{\mathrm{b}}$ & $3.6^{\mathrm{b}}$ & \\
\hline \multirow[t]{4}{*}{ Micali et al ${ }^{60}$} & $14-16$ & 6,140 & 3,416 & 2,742 & 2-part & DSM-5 & $0.5^{\mathrm{a}}$ & $0.6 \mathrm{I}^{\mathrm{a}}$ & $0.33^{\mathrm{a}}$ \\
\hline & & 5,069 & 3,059 & 2,154 & question & & $0.03^{b}$ & $0.03^{b}$ & $0.04^{\mathrm{b}}$ \\
\hline & & & & & & & $1.15^{\mathrm{a}}$ & $1.15^{\mathrm{a}}$ & $0.6^{\mathrm{a}}$ \\
\hline & & & & & & & $0.42^{\mathrm{b}}$ & $0.72^{\mathrm{b}}$ & $0^{\mathrm{b}}$ \\
\hline \multirow[t]{2}{*}{ Lee-Winn et al ${ }^{10}$} & $13-18$ & 9,336 & 4,738 & 4,598 & EDDI & DSM-5 & $0.78^{\mathrm{a}}$ & $1 . \mathrm{I}^{\mathrm{a}}$ & $0.46^{\mathrm{b}}$ \\
\hline & & & & & & & $1.33^{\mathrm{b}}$ & $1.2^{\mathrm{b}}$ & $1.47^{\mathrm{b}}$ \\
\hline
\end{tabular}

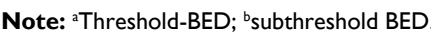

Abbreviations: BED, binge eating disorder; ChEDE, Child Eating Disorders Examination; CIDI, Composite International Diagnostic Interview; DSM-IV, Diagnostic and Statistical Manual of Mental Disorders, 4th Edition; DSM-5, Diagnostic and Statistical Manual of Mental Disorders, Fifth Edition; EAT, Eating Attitudes; EDDI, Eating Disorder Diagnostic Interview; EDE-Q, Eating Disorder Examination-Questionnaire; SEDs, Survey for Eating Disorders.

adolescent samples of their previous study, ${ }^{40}$ but considering the new DSM-5 criteria, finding an increased prevalence of BED of $\sim 2 \%$. Two other studies ${ }^{10,60}$ have replicated similar results but considering also male adolescents. One study ${ }^{60}$ was consistent with the previous findings, underlining that female adolescents had a higher prevalence of BED and SBED with respect to their peer male adolescents. In contrast, another study ${ }^{10}$ has evidenced a higher rate of BED among female adolescents, but male adolescents reported higher rate of SBED.

\section{Impact of BED on physical, psychological, and social functioning}

As seen in the above paragraph, epidemiological research has underlined that BED is common in adolescent population. Research that has focused on the possible consequences of BED on physical, psychological, and social functioning has evidenced that adolescents suffering from BED have an increased risk of developing a variety of adverse outcomes, which may persist into young adulthood. ${ }^{63}$
Specifically, we reported data from 12 studies showing that BED in adolescence was predictive of a broad spectrum of negative outcomes, including obesity, ${ }^{39,60,61,64}$ social impairment, ${ }^{18,64,65}$ other psychological difficulties, especially depressive symptoms, ${ }^{39,59-61,64,67,68}$ anxiety, ${ }^{60,68}$ and emotional distress, ${ }^{32,40,68}$ substance use, ${ }^{39,60,61}$ and propensity to suicide and deliberate self-harm ${ }^{18,32,60,66}$ (Table 3).

Regarding the impact of BED on physical health, four prospective cohort studies ${ }^{39,60,61,64}$ have underlined that BED was predictive of overweight and obesity, both in girls and boys. ${ }^{39,60,64}$ In particular, in early adolescents with BED, it has been reported a body mass index (BMI) of $\sim 23 \mathrm{~kg} / \mathrm{m}^{2},{ }^{59}$ is indicative of a healthy weight. However, among this population, BMI tended to increase during later adolescence, with a mean score of $27 \mathrm{~kg} / \mathrm{m}^{2}$ among youths with $\mathrm{BED}^{59}$ and of 26 $\mathrm{kg} / \mathrm{m}^{2}$ for SBED, ${ }^{32}$ representative of a overweight condition $\left(25<\mathrm{BMI}<29.9 \mathrm{~kg} / \mathrm{m}^{2}\right)$, up to a rate of $60 \%$ of obese (BMI $\left.>30 \mathrm{~kg} / \mathrm{m}^{2}\right),{ }^{31}$ suggesting that binge eating might represent a crucial risk factor for obesity. A study by Field et al ${ }^{61}$ has shown that $35.1 \%$ of female adolescents became overweight 
Table 3 Binge eating and physical, social, and psychological outcomes

\begin{tabular}{|c|c|c|c|c|}
\hline Reference & $\begin{array}{l}\text { Age } \\
\text { (years) }\end{array}$ & $\begin{array}{l}\text { Sample } \\
\text { (N) }\end{array}$ & Outcome & $\begin{array}{l}\text { Results (OR; } 95 \% \mathrm{Cl} \text { ) or ( } p \text {-value) or } \\
\text { (Cohen's } d) \text { or }(\%)\end{array}$ \\
\hline Field et $\mathrm{a}^{61}$ & $16-24$ & 859 & $\begin{array}{l}\text { Overweight/obesity } \\
\text { Use drugs } \\
\text { Binge drink } \\
\text { Depressive symptoms }\end{array}$ & $\begin{array}{l}\text { BED was predictive of overweight/obesity (OR: I.9; Cl: I.0-3.5) and } \\
\text { depressive symptoms (OR: } 2.3 ; \mathrm{Cl}: \text { I.0-5.0) in female adolescents. No } \\
\text { association was found with binge drinking }\end{array}$ \\
\hline $\begin{array}{l}\text { Sonneville } \\
\text { et } \mathrm{al}^{39}\end{array}$ & $12-24$ & 14,166 & $\begin{array}{l}\text { Overweight/obesity } \\
\text { Use drugs } \\
\text { Binge drink } \\
\text { Depressive symptoms }\end{array}$ & $\begin{array}{l}\text { Binge eating was significantly associated with incident overweight/obesity } \\
\text { (OR: I.73; Cl: I.I I-2.69), starting to use marijuana (OR: I.85; Cl: I.27- } \\
\text { 2.67) and other drugs (OR: I.59; Cl: I.08-2.33), and with the onset of } \\
\text { high depressive symptoms among both female adolescents (OR: } 2.12 \text {; Cl: } \\
\text { I.32-3.40) and male adolescents (OR: } 3.2 \text { I; Cl: } 0.68-15.27 \text { ) }\end{array}$ \\
\hline Micali et al ${ }^{64}$ & $13-15$ & 7,082 & $\begin{array}{l}\text { Overweight/obesity } \\
\text { Social impairment } \\
\text { Family burden } \\
\text { Emotional-behavioral disorders }\end{array}$ & $\begin{array}{l}\text { Bingeing/overeating was predictive of higher BMI } z \text { scores at I } 5 \text { years of age } \\
(p<0.000 \mathrm{I}) \text {, both in adolescent girls and boys. Bingeing/overeating in girls was } \\
\text { associated with social impairment }(p<0.000 \mathrm{I}) \text {, burden to parents }(p<0.000 \mathrm{I}) \text {, } \\
\text { and both emotional }(p<0.0 \mathrm{I}) \text { and behavioral }(p<0.0 \mathrm{I}) \text { disorder } \\
\text { In male adolescents, bingeing/overeating was associated with social } \\
\text { impairment ( } p<0.000 \mathrm{I}) \text {, family burden }(p<0.000 \mathrm{I}) \text {, and both emotional } \\
(p<0.000 \mathrm{I}) \text { and behavioral }(p<0.000 \mathrm{I}) \text { disorder }\end{array}$ \\
\hline Micali et al ${ }^{60}$ & $14-16$ & 6,140 & $\begin{array}{l}\text { Overweight/obesity } \\
\text { Depression } \\
\text { Anxiety } \\
\text { Alcohol use } \\
\text { Substance use } \\
\text { Self-harm }\end{array}$ & 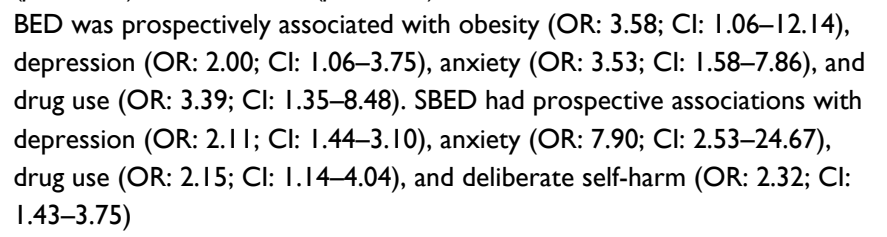 \\
\hline $\begin{array}{l}\text { Ranzenhofer } \\
\text { et al }{ }^{65}\end{array}$ & $12-17$ & 158 & $\begin{array}{l}\text { Depressive symptoms } \\
\text { Health } \\
\text { Social/interpersonal functioning } \\
\text { Work/school } \\
\text { Mobility } \\
\text { Self-esteem } \\
\text { Activities of daily living }\end{array}$ & $\begin{array}{l}\text { BED was associated with depressive symptoms }(p<0.05) \text {, health }(p<0.05) \text {, } \\
\text { mobility }(p<0.05) \text {, and self-esteem }(p<0.01) \text {. Adolescent girls, compared to } \\
\text { boys, reported lower levels of activities of daily living, mobility, self-esteem, } \\
\text { and social/interpersonal functioning }(p<0.05) \text {, but not health or work/school }\end{array}$ \\
\hline $\begin{array}{l}\text { Swanson } \\
\text { et } \mathrm{al}^{18}\end{array}$ & $13-18$ & 10,123 & $\begin{array}{l}\text { Mental health } \\
\text { Social impairment } \\
\text { Suicidality }\end{array}$ & 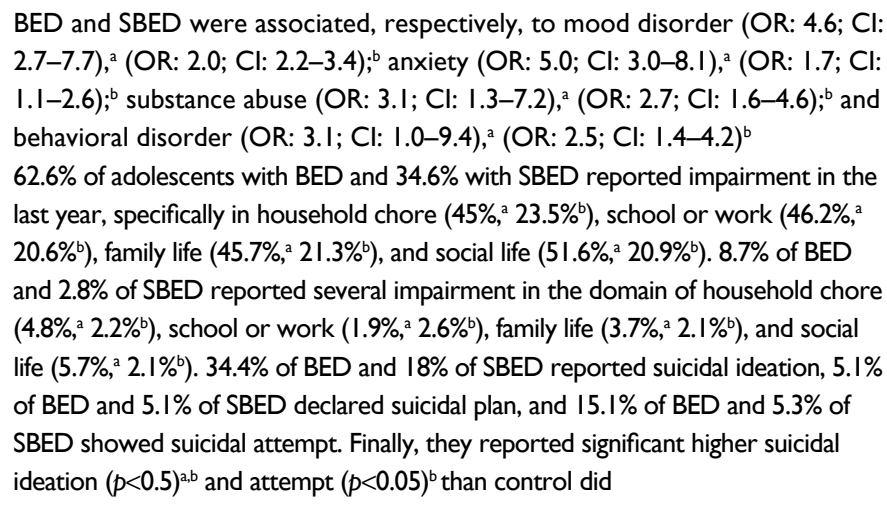 \\
\hline $\begin{array}{l}\text { Skinner } \\
\text { et al }{ }^{67}\end{array}$ & $12-23$ & 4,798 & Depressive symptoms & $\begin{array}{l}\text { Female adolescents with binge eating or overeating had a higher risk to } \\
\text { develop depressive symptoms after } 2 \text { years (OR: I.9; Cl: I.2-2.9 and OR: } \\
\text { I.9; Cl: I.I-3.4, respectively). } \\
\text { Female adolescents with depressive symptoms at baseline had a higher risk to } \\
\text { start binge eating (OR: } 2.3 ; \mathrm{Cl}: \text { I.7-3.0) or overeating (OR: I.9; Cl: I.4-2.5) at } \\
\text { follow-up }\end{array}$ \\
\hline Allen et a $1^{59}$ & $14-20$ & 1,383 & $\begin{array}{l}\text { Depressive symptoms } \\
\text { Physical quality of life } \\
\text { Mental quality of life }\end{array}$ & $\begin{array}{l}\text { BED was longitudinally associated with depressive symptoms }(p<0.05) \\
\text { and poor mental health quality of life }(p<0.05) \text {, in both male and female } \\
\text { adolescents }\end{array}$ \\
\hline Allen et a ${ }^{68}$ & $14-20$ & $\mathrm{I}, 383$ & $\begin{array}{l}\text { Depression } \\
\text { Anxiety } \\
\text { Psychological functioning }\end{array}$ & $\begin{array}{l}\text { BED was significantly and longitudinally associated with depressive }(p<0.0 I \text {; } \\
d=0.73) \text {, anxiety }(p<0.01 ; d=1.25) \text {, and stress }(p<0.01 ; d=I .3 I) \text { symptoms and } \\
\text { poor mental quality of life }(p<0.01 ; d=0.83) \text { in adolescents with BED }\end{array}$ \\
\hline Stice et $\mathrm{al}^{40}$ & $12-20$ & 496 & $\begin{array}{l}\text { Mental health service use } \\
\text { Functional impairment } \\
\text { Emotional distress }\end{array}$ & $\begin{array}{l}\text { Adolescents with BED and SBED reported more mental health treatment } \\
(p<0.0 \mathrm{I}) \text {, functional impairment }(p<0.05) \text {, and emotional distress }(p<0.0 \mathrm{I}) \\
\text { than the control group }\end{array}$ \\
\hline
\end{tabular}


Table 3 (Continued)

\begin{tabular}{|c|c|c|c|c|}
\hline Reference & $\begin{array}{l}\text { Age } \\
\text { (years) }\end{array}$ & $\begin{array}{l}\text { Sample } \\
\text { (N) }\end{array}$ & Outcome & $\begin{array}{l}\text { Results (OR; } 95 \% \mathrm{CI}) \text { or ( } p \text {-value) or } \\
\text { (Cohen's } d) \text { or }(\%)\end{array}$ \\
\hline Stice et $\mathrm{al}^{32}$ & $15-23$ & 496 & $\begin{array}{l}\text { Functional impairment } \\
\text { Emotional distress } \\
\text { Suicidality } \\
\text { Mental health service utilization }\end{array}$ & $\begin{array}{l}\text { BED was significantly associated with functional impairment }(p<0.0 \mathrm{I} ; d=I .06) \text {, } \\
\text { emotional distress }(p<0.0 \mathrm{I} ; d=I .22) \text {, suicidality }(p<0.0 \mathrm{I} ; d=I . I 4) \text {, and mental } \\
\text { health treatment }(p<0.0 \mathrm{I} ; d=\mathrm{I} .10) \text {. SBED was associated only with emotional } \\
\text { distress }(p<0.0 \mathrm{I} ; d=0.94) \text { and suicidality }(p<0.0 \mathrm{I} ; d=0.5 \mathrm{I})\end{array}$ \\
\hline $\begin{array}{l}\text { Forrest } \\
\text { et } \mathrm{al}^{66}\end{array}$ & $13-18$ & 10,123 & Suicidality & $\begin{array}{l}\text { BED was associated with elevated odds of suicidal ideation (OR: } 3.8 \mathrm{I} ; \mathrm{Cl} \text { : } \\
2 . \mathrm{I4}-6.77 ; p<0.00 \mathrm{I}) \text { and attempting (OR: } 5.0 \mathrm{I} ; \mathrm{Cl} \text { : I.62-I5.48; } p<0.0 \mathrm{I})\end{array}$ \\
\hline
\end{tabular}

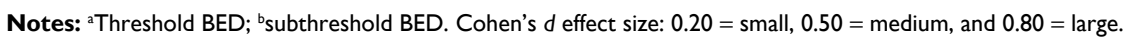

Abbreviations: $\mathrm{BED}$, binge eating disorder; $\mathrm{BMI}$, body mass index; $\mathrm{Cl}$, confidence interval; OR, odds ratio; SBED, subthreshold binge eating disorder.

and/or obese over the following years, with a significant higher incidence compared with their peers with other EDs. Three other longitudinal studies ${ }^{39,60,64}$ have reported similar findings for both female and male adolescents, evidencing that binge eating symptoms are predictive of negative physical consequences (such as obesity) among both sexes.

Furthermore, research has underlined that the impact of BED in adolescence reaches beyond physical adverse outcomes. In particular, we considered three studies ${ }^{18,64,65}$ that have suggested that the presence of BED was predictive of a broad spectrum of negative social/interpersonal and outcomes and lower quality of life, in both obese and general adolescent population. A study by Ranzenhofer et a ${ }^{65}$ focused on an obese adolescent population has shown that binge eating youths reported severe impairments in the domains of health, mobility, and self-esteem compared with their peers without binge eating, even after controlling for body composition. At the same time, two studies ${ }^{18,64}$ have replicated similar results also in population-based samples, evidencing that bingeing/overeating symptoms were significantly associated with both social impairment and family burden, in girls and boys. As regards possible different impact of BED and SBED on adolescents' quality of life, one study ${ }^{64}$ has evidenced that $62.6 \%$ of adolescents with BED and 34.6\% of adolescents with SBED reported impairment in the past year, especially in the domains of social life and household chore, respectively. About $9 \%$ of adolescents with BED had severe impairments, particularly in social life, while $2.8 \%$ of those with SBED reported severe school or work impairment. Although the research design did not allow causal links, it represented the first population-based study focused on the impact of both threshold and subthreshold of BED in a large population-based samples of female and male adolescents.

With specific regards to the effects on psychological health, we have identified eight studies ${ }^{18,39,40,59-61,67,68}$ that have underlined that BED in adolescence is associated with various adverse mental health outcomes, especially anxiety and depressive symptoms. Two studies ${ }^{61,67}$ have focused on community sample groups of female adolescents, evidencing a strong association between BED and depressive symptoms. Moreover, in comparison with the other subtype of EDs, BED was the only one illness predictive of depressive symptoms. ${ }^{61}$ A study by Skinner et $a l^{67}$ has shown that prospective associations between binge eating and depressive symptomatology had similar strength in both directions, suggesting the presence of a bidirectional relationship between these two psychopathological difficulties.

More recently, three studies ${ }^{39,59,68}$ have confirmed these associations also for adolescent boys. One of them ${ }^{39}$ has reported a higher power of prospective associations between BED and depressive symptoms among boys. Moreover, these studies have also evidenced an expanded range of adverse psychological health outcomes predicted by BED, including anxiety and stress symptoms, substance use, and a general low quality of life. However, associations with stress and anxiety symptoms had large effect size. ${ }^{68}$

Given that prevalence studies have underlined that SBED is very frequent in adolescent population, we considered four studies ${ }^{18,32,40,60}$ that have examined the impact of both BED and SBED on psychological well-being. Two longitudinal studies $^{32,40}$ on female adolescent community sample have reported that youths with both BED and SBED showed higher mental health difficulties, functional impairment, and emotional distress, than controls did, with no significant differences between the two forms of disease respect to these variables. Consistent with previous studies, a cross-sectional study by Swanson et $\mathrm{al}^{18}$ on a community sample of adolescent girls and boys found significant associations between both BED and SBED with mood disorder, anxiety, alcohol, and drug use, in female and male adolescents (aged 13-18 years). In this study, adolescents with BED showed more difficulties in the area of anxiety, while those with SBED 
were associated with a higher risk for alcohol and drug use. Another study ${ }^{60}$ confirmed similar results even longitudinally, reporting that the main significant associations were between SBED and both anxiety and depressive symptoms.

Finally, given that research has underlined clinically significant impairment of BED in adolescence, in terms of physical and mental health difficulties, we considered four studies ${ }^{18,32,60,66}$ that have also examined its possible impact on suicidality (in terms of suicidal ideation, suicidal thoughts, and suicidal attempts) or self-injury. Two studies ${ }^{18,32}$ found significant associations between BED and SBED and suicidality in female and male adolescents, with a higher effect size for BED. Another study ${ }^{60}$ has evidenced that SBED, but not BED, was prospectively significantly associated with deliberate self-harm. Finally, a recent study by Forrest et $\mathrm{al}^{66}$ has reported that the majority of adolescents with BED reported that suicidal ideation followed BED onset, suggesting that binge eating might represent an important risk factor for suicidality in adolescent population.

\section{Psychological treatment strategies}

Despite the high prevalence of BED in adolescent populations and the severe physical, social, and psychological associated outcomes, systematic studies on possible and effective psychological treatment for BED among young population are scarce.

Several psychological intervention options have been studied for the treatment of BED in adulthood, ${ }^{69}$ such as 1) cognitive behavioral therapy (CBT), ${ }^{70-72}$ which concentrates on changing dysfunctional patterns of eating-related thinking and behaviors; 2) behavioral weight loss treatment, ${ }^{73}$ which are specifically focused on physical activity and modifying diet to reduce overweight and obesity; 3 ) interpersonal psychotherapy (IPT), ${ }^{69,75}$ a short-term psychotherapy focused on reducing interpersonal difficulties associated with the onset and/or maintenance of BED; and 4) dialectical behavior therapy (DBT), ${ }^{76,77}$ which is directly focused on emotional dysregulation and difficulties in coping with one's own emotions, by promoting the capacity to recognizing, tolerating, and regulating their emotions and mood states. ${ }^{78}$ Notwithstanding research has demonstrated their efficacy in reducing binge eating in the short and long term, to date, very few studies have examined the possible effectiveness of these psychological interventions also in adolescents with BED. In particular, we found only six studies ${ }^{79-84}$ that have developmentally adapted these treatments to adolescent girls and in small samples. Two of them ${ }^{79,80}$ have examined the effectiveness of CBT, two ${ }^{81,82}$ are focused on IPT and the other two ${ }^{83,84}$ have used DBT (Table 4). We found that no study has focused on psychological intervention on male adolescents.

With regard to CBT studies, DeBar et al ${ }^{79}$ have used an adolescent adaptation of CBT in a sample of female adolescents with BED (52\%), recurrent binge eating episodes $(32 \%)$, or bulimia spectrum disorders $(16 \%)$. Subjects in CBT group were compared with a usual-delayed treatment (TAU-DT) control group $(\mathrm{N}=13)$, in which adolescents received CBT 6 months later. All participants were assessed at baseline and at 3-and 6-month follow-up sessions. Female adolescents in CBT group showed significantly higher abstinence of binge eating episodes at 3- and 6-month follow-up than their peers of TAU-DT group, with a robust effect size. At follow-up, totality of participants of CBT was abstinent. Moreover, the intervention also produced significant improvements in other shape-, weight-, and eating-related concerns, although with a smaller effect size. Finally, girls in the CBT group showed a significant lower depressive symptoms at both the follow-up sessions. However, subjects of TAU-DT group, who were additionally followed up at 9 and 13 months, reported similar outcomes. Although this study provided a preliminary evidence of the efficacy of CBT in reducing binge eating symptoms and their secondary outcomes among adolescent population, homogeneity and small size of sample did not permit generalizability of these findings. Another study by Jones et $\mathrm{al}^{80}$ has investigated the use of an Internet-facilitated CBT-self-help intervention along 16 weeks, compared to a 9-month-wait-list control (WLC) group, for weight maintenance and the reduction of binge eating episodes. In particular, the treatment program was composed by an integrated intervention in which behavioral weight loss (BWL) was combined with CBT. This choice was due to the evidence that in adolescence the specific increased focus on body weight, control of eating behaviors, and dietary that characterizes traditional weight loss programs ${ }^{73}$ could produce the paradoxical effect of increasing the risk and/or severity of ED symptomatology. ${ }^{85}$ Moreover, despite traditional BWL programs being found to be effective in the treatment of BED in adults, ${ }^{74}$ they are specifically focused on the objective overeating episodes, neglecting the aspects of loss of control which are particularly central in BED in adolescence. ${ }^{37}$ Subjects in CBT group showed significantly lower BMI and BMI $z$ scores at follow-up assessment, a greater decrease in both objective and subjective binge episodes at both posttreatment and follow-up assessments, and a significant reduction of weight- and shape-related concerns than control did, supporting the effectiveness of this intervention also in female adolescents with BED. 
Table 4 Psychological treatment studies for adolescents with BED

\begin{tabular}{|c|c|c|c|c|c|c|}
\hline \multirow[t]{2}{*}{ Reference } & \multirow{2}{*}{$\begin{array}{l}\text { Age } \\
\text { (years) }\end{array}$} & \multirow{2}{*}{$\begin{array}{l}\text { Psychological } \\
\text { treatment }\end{array}$} & \multirow[t]{2}{*}{ Control group } & \multicolumn{2}{|c|}{ Sample (N) } & \multirow[t]{2}{*}{ Results (OR: $95 \% \mathrm{Cl}$ ) or ( $p$-value) or (Cohen's $d$ ) or (\%) } \\
\hline & & & & $\overline{\text { EG }}$ & $\overline{\mathbf{C G}}$ & \\
\hline DeBar et a $7^{79}$ & $12-18$ & $\begin{array}{l}\text { CBT (8 sessions } \\
\text { over } 6 \text { months) }\end{array}$ & TAU-DT & 13 & 12 & $\begin{array}{l}\text { CBT participants had a significant higher rate of abstinence } \\
\text { from recurrent binge eating at } 3 \text { months }(p<0.01 \text { ) and at } 6 \\
\text { months ( } p<0.01 ; d=1.467) \text {, a significant greater improvement } \\
\text { in eating-related concerns ( } p<0.05 ; d=0.80) \text {, shape-related } \\
\text { concerns ( }(<<0.01 ; d=1.04) \text {, and weight-related concerns } \\
\text { ( } p<0.01 ; d=0.64) \text { and significant higher reduction in depressive } \\
\text { symptoms ( } p=0.05 \mathrm{I} ; d=0.57) \text { at both } 3 \text { and } 6 \text { months }\end{array}$ \\
\hline Jones et al ${ }^{80}$ & 15 & $\begin{array}{l}\text { Internet-facilitated } \\
\text { CBT-self-help } \\
\text { intervention (16 } \\
\text { session over } 16 \\
\text { weeks) }\end{array}$ & WLC & 52 & 53 & $\begin{array}{l}\text { Internet-facilitated CBT-self-help intervention was associated } \\
\text { with a significant reduction of BMI } z \text { scores }(p<0.0 \mathrm{I} ; d=0.80) \\
\text { and BMI }(p<0.0 \mathrm{I} ; d=0.60) \text { at } 9 \text {-month follow-up assessment, a } \\
\text { significant decrease of objective and subjective binge episodes } \\
\text { at both posttreatment assessment ( } p<0.0 \mathrm{I}) \text { and follow-up } \\
\text { assessment }(p<0.05) \text { and a significant lower weight- and shape- } \\
\text { related concerns }(p<0.05)\end{array}$ \\
\hline $\begin{array}{l}\text { Tanofsky- } \\
\text { Kraff et al }{ }^{81}\end{array}$ & $12-17$ & $\begin{array}{l}\text { IPT ( } 12 \text { sessions } \\
\text { over } 12 \text { weeks) }\end{array}$ & $\mathrm{HE}$ & 19 & 19 & $\begin{array}{l}\text { IPT was associated with significant reduction in LOC episodes } \\
\text { at } 6 \text {-month follow-up }(p<0.05) \text { and in BMI }(p<0.05) \text { over I year }\end{array}$ \\
\hline $\begin{array}{l}\text { Tanofsky- } \\
\text { Kraff et al }\end{array}$ & $12-17$ & $\begin{array}{l}\text { IPT (12 sessions } \\
\text { over } 12 \text { weeks) }\end{array}$ & $\mathrm{HE}$ & 56 & 60 & $\begin{array}{l}\text { Both IPT and HE were associated with a significant decrease } \\
\text { in expected BMI gain }(p<0.00 \mathrm{I}) \text {, BMI } z \text { score }(p=0.003) \text {, } \\
\text { BMI percentile }(p<0.00 \mathrm{I}) \text {, anxiety and depressive symptoms } \\
(p<0.00 \mathrm{I}) \text {, and the frequency of LOC episodes }(p<0.00 \mathrm{I}) \text { over } \\
\text { I } 2 \text {-month follow-up. IPT was associated with a significant } \\
\text { higher reduction of objective binge eating }(p<0.05) \text { at the } \\
\text { I2-month follow-up }\end{array}$ \\
\hline Safer et al ${ }^{83}$ & 16 & $\begin{array}{l}\text { DBT ( } 30 \text { sessions } \\
\text { over } 6 \text { months) }\end{array}$ & None & 1 & 0 & $\begin{array}{l}\text { DBT was associated with decreased binge eating episodes by } \\
\text { the end of treatment and abstinence at 3-month follow-up }\end{array}$ \\
\hline Mazzeo et al ${ }^{84}$ & $13-17$ & $\begin{array}{l}\text { DBT ( } 12 \text { sessions } \\
\text { over } 12 \text { weeks) }\end{array}$ & BWT & 28 & 17 & $\begin{array}{l}\text { DBT and BWT were associated with significant reductions } \\
\text { in eating-related concern }(p<0.05) \text {, shape-related concern } \\
(p<0.05) \text {, restraint }(p<0.05) \text {, global disordered eating attitudes } \\
(p<0.05) \text {, and negative }(p<0.05) \text { effect }\end{array}$ \\
\hline
\end{tabular}

Notes: Cohen's $d$ effect size: $0.20=$ small, $0.50=$ medium, and $0.80=$ large.

Abbreviations: BET, binge eating disorder; BMI, body mass index; BWT, behavioral weight loss treatment; CBT, cognitive behavioral therapy; CG, control group; CI, confidence interval; DBT, dialectical behavior therapy; EG, experimental group; HE, health education; IPT, interpersonal psychotherapy; LOC, loss of control; OR, odds ratio; TAU-DT, treatment as usual-delayed treatment; WLC, wait-list control.

Regarding IPT that has been suggested to be an important strategy to reduce binge eating and associated interpersonal problems, ${ }^{69}$ we found only two studies ${ }^{81,82}$ that evaluated its effectiveness in adolescents with BED. A pilot study by Tanofsky-Kraff et al ${ }^{81}$ focused on IPT in a sample of female adolescents who were at-risk for excessive weight gain, with and without $L O C$ eating, and reported a significant reduction in LOC episodes at 6-month follow-up and in BMI over 1 year, compared with girls randomly assigned to a standardof-care health education (HE) program group. However, as in most pilot studies, the absence of statistical power did not allow generalizable conclusions on the reported effectiveness. Consequently, more recently, the same authors ${ }^{82}$ conducted an adequately powered clinical trial to verify the effectiveness of an adapted IPT group of girls compared to an HE control group. Adolescents of both the groups reported significant reduction of dimensions of BMI (expected BMI gain, BMI $z$ score, and BMI percentile), anxiety and depressive symptomatology, and LOC episodes over 1-year follow-up, with no differences between groups. However, girls in IPT group have shown a significant decrease of binge eating episodes at 12-month follow-up.

Finally, we reported two studies ${ }^{83,84}$ specifically interested in examining the effectiveness of DBT in reducing binge eating symptoms. One of them, Safer et al's study, ${ }^{83}$ was a case report of a 16-year-old girl, who has shown a significant reduction of binge eating episodes after treatment, and abstinence from binging at 3-month follow-up. Despite potential limitations of case-control studies, we considered this study because it provided a preliminary support for the utility of the adolescent modified version of DBT in reducing binge eating episodes. Finally, Mazzeo et $\mathrm{al}^{84}$ examined the effectiveness of DBT in adolescent girls, compared to a BWL treatment control group, reporting a significant reduction 
in eating-related concern, shape-related concern, restraint, global disordered eating attitudes, and negative effect in both the groups.

\section{Summary \\ What is the prevalence of BED in adolescence?}

BED has only recently been introduced into the psychiatric nomenclature, and consequently, epidemiological research of this ED in adolescence is in the early stages. Prevalence rate for BED was reported in 13 studies, five of them ${ }^{18,40,51-53}$ using DSM-IV criteria and eight of them ${ }^{10,31,32,39,59-62}$ using the DSM-5 criteria. Altogether, our review of the literature on the prevalence of BED has shown that this disorder is very common in adolescence phase, with a rate approximately ranging from $1 \%$ to $5 \%$. Moreover, one study ${ }^{18}$ has also examined the incidence of BED in female adolescent populations, reporting a rate of 343 per 100,000 persons.

Although most studies have been conducted with the samples of teenage girls, nine studies ${ }^{10,18,31,39,51-53,59,60}$ have focused on both the sexes, reporting significant sex-related differences. In particular, girls showed a higher risk for BED than boys ( $1 \%-4 \% ; 0 \%-1.2 \%$, respectively). ${ }^{31,39,52,53,57}$ However, this sex-related difference was less pronounced in other EDs. ${ }^{86}$ For this reason, BED represents the most common ED among male adolescent population. ${ }^{87}$ Moreover, longitudinal studies that we reviewed have evidenced that the prevalence of BED tended to increase over time, with a peak at 19-22 years of age for female adolescents ${ }^{39,61}$ and at 24 years for male adolescents. ${ }^{39}$

Interestingly, it has been evidenced that in adolescents, BED frequently manifests in attenuated, subclinical forms. ${ }^{18,38,39}$ Indeed, studies with subthreshold adolescents ${ }^{10,18,32,40,60}$ found a twofold BED prevalence. Moreover, the prevalence in male adolescents was lower than that in female adolescents also with respect to SBED diagnoses, with $0.3 \%-4.6 \%$ in girls and $0 \%-2.3 \%$ in boys. ${ }^{10,18,60}$

However, the validity of some of the reviewed studies can be questioned, because the prevalence rate and the definition itself of binge eating may differ depending on the assessment measurements used by researchers. In particular, studies that have used self-report assessments ${ }^{52,53,59,61}$ tended to report higher prevalence than interview-based studies. . $^{18,31,32,39,40,62}$ This may depend on the fact that interviews may allow clarifying the subjective experience of "lack of control overeating" and objectively measure the "large food consumption," which represent two key criteria for the clinical diagnosis of BED. Other specific problems are the general tendency of individuals suffering from BED to hide their illness, the limited awareness of the clinical relevance of their disordered eating, and, consequently, the difficulty to seek for professional help. ${ }^{18,88}$ For these reasons, future studies on large sample of adolescents from the general population are needed.

\section{What are the physical, social, and psychological outcomes of BED in adolescence?}

Research in the last decade has documented the clinical significance of BED in terms of adverse physical, social, and psychological health problems commonly associated with this condition. In particular, with regard to physical outcomes, several studies have reported that BED and SBED, in both female and male adolescents, were predictive of high rates of overweight and obesity. ${ }^{39,60,61,64}$ This finding supports the view of clinical significance of binge eating, given the important consequences on health associated with obesity in adolescent and adult populations. Indeed, international research has evidenced that obesity is associated with an increased risk to develop severe medical conditions, such as type II diabetes mellitus (DM), hypertension, cardiovascular disease, fatty liver disease, and a higher risk for morbidity and mortality. ${ }^{89}$

However, many studies have underlined that the impact of BED leads to an increased risk of developing a variety of adverse social and emotional-behavioral outcomes, in both obese and population-based adolescent samples. ${ }^{18,65}$ In particular, the cross-sectional and prospective studies that we considered here have evidenced that both BED and SBED significantly affect health-related quality of life, with marked impairment especially in social and family relationships, and are also associated with negative self-esteem. ${ }^{64,65}$ More specifically, adolescents with BED tended to show more difficulties in social/interpersonal functioning and work/ school achievements, while SBED was strongly associated especially with lower quality of general daily living and family burden. ${ }^{18,39,40,59-61,67,68}$ Although these consequences of binge eating may be similar for both female and male adolescents, female adolescents reported the highest levels of impairment. ${ }^{18,64,65}$

Moreover, the studies we reviewed have also evidenced a growing interest in examining possible associations of BED with psychiatric comorbidities. These studies have evidenced that BED in adolescence is a strong predictor of a large spectrum of mental health difficulties. Most of them showed prospective associations with internalizing problems, 
especially depressive (reported by $\sim 45 \%$ of subjects with BED), anxiety, and distress symptoms (as displayed by about one third of adolescents with BED), ${ }^{18,59-61,64,65,67}$ and suggesting a higher impact on male adolescents. ${ }^{39}$ Substance use also seems to affect one fourth of subjects with BED. ${ }^{18,39,60}$

Finally, a few studies have also examined the possible impact of BED on suicidality. ${ }^{18,32,60,66}$ To date, research in this field is scarce, but some studies suggested that adolescents with either BED or SBED, as well as other EDs, ${ }^{90}$ had a higher risk of suicidal ideation and attempts than non-eatingdisordered youths. In particular, suicidal ideation is found in $\sim 30 \%$ adolescents with BED and $20 \%$ with SBED, and the frequency of suicidal attempts was $15.1 \%$ and $5.3 \%$, respectively. ${ }^{18,32,66}$ The presence of several self-harm behaviors among BED adolescents has also been evidenced. ${ }^{60}$ Moreover, although BED is found to co-occur with several mental disorders that are known to increase mortality risks, ${ }^{91,92}$ to our knowledge no study has so far been published to systematically examine the effects of BED on mortality.

\section{What is the effectiveness of existing psychological interventions for BED in the adolescent population?}

To date, evidence for effective treatments for adolescents with $\mathrm{BED}$ is growing but yet scarce and inconsistent. This may be due to the fact that BED has only recently been included as a diagnostic category in DSM-5, and, consequently, attention of clinicians on specific intervention in this area is at its dawn.

However, as our review has shown, in the last decade, researchers and clinicians have developmentally adapted some of the intervention approaches that proved effective for the treatment of BED in adult samples. ${ }^{67-73}$ In particular, we have identified some small trials of CBT, ${ }^{79,80} \mathrm{IPT},{ }^{81,82}$ and $\mathrm{DBT}^{83,84}$ involving adolescents and young adults with BED.

In accordance with the NICE guidelines, ${ }^{93} \mathrm{CBT}$ is recommended to be the standard treatment for adult subjects suffering from BED, and our review has confirmed its effectiveness in reducing binge eating symptoms and the severity of risk factors also among adolescent population. ${ }^{79}$ Moreover, it has also been evidenced that Internet-based CBT interventions ${ }^{80}$ can provide a valid support, especially in the early phase of the syndrome. Furthermore, online interventions have been shown to have many advantages for their accessibility, due to the reduced cost and time required, and they may also facilitate adolescent help-seeking. Also the few studies that have used adolescent-adapted IPT $^{81,82}$ and $\mathrm{DBT}^{83,84}$ have reported findings that seem promising in reducing both binge eating problems and co-occurring mental health symptoms.
Interestingly, some interventions have also favored weight loss or a weight maintenance. Given that adult population with BED has been evidenced that overweight typically followed the onset of binge BED, ${ }^{94}$ previous findings underlined that an early identification and intervention on binge eating in adolescence may reduce the risk of excessive weight gain and, thus, help to prevent adult obesity.

Notwithstanding the studies we reviewed have evidenced some positive preliminary results in reducing binge eating episodes and associated psychopathological symptoms, all of them had small sample size and relatively short follow-up intervals, precluding definitive conclusions about their effectiveness and appropriateness, and suggesting the necessity of implementing long-term longitudinal studies to verify the persistence of clinical benefits over time. Furthermore, additional research comparing these different methodological interventions is needed.

Moreover, to the best of our knowledge, no study has yet been conducted to confirm the effectiveness of psychological treatment in male adolescents with BED.

Finally, it is important to emphasize that epidemiological studies have suggested that only a small percentage of adolescents with BED (specifically, 11.9\%) tended to seek clinical help. ${ }^{18}$ Moreover, the high rate of adolescents who do not meet full-threshold criteria, although they are affected by various severe physical and psychological negative consequences, makes it even harder to identify them, suggesting the importance of implementing primary prevention programs aimed at increasing awareness, reducing stigma, and promoting acceptance of intervention.

\section{Conclusion}

International research has underlined that adolescence is characterized by a high risk for the onset of BED, which represents the most common ED subtype among youths, posing severe risks to their physical and mental health. Several studies have evidenced the complex etiopathogenesis of BED, which seems to result from dynamic and reciprocal relationships between different type of variables, including biological (in particular, familial genetic predisposition and epigenetic processes), ${ }^{95,96}$ psychological (such as personality traits of perfectionism and impulsivity, negative effect or depressive symptoms, weight and eating concerns, and body dissatisfaction), ${ }^{98-100}$ and environmental risk factors, in terms of parental influences on childhood eating behavior, ${ }^{95}$ parental psychopathology and psychopathological risk, ${ }^{101}$ early adverse experiences, and the presence of traumatic experiences in the parents. ${ }^{102}$ Among individual risk factor, 
it has also been reported that dietary restraint, a general rigid eating habits and maladaptive weight control behaviors represent significant risk factor for the onset of BED. ${ }^{103}$ Moreover, many studies have reported the predictive role played by peer influences and perception of a lack of peer support, ${ }^{104,105}$ as well as by cultural influences (especially social pressure for thinness and the resulting body dissatisfaction) $)^{97,106}$ on the onset of BED. Overall, these findings suggest the importance of implementing longitudinal studies and randomized controlled trials to increase our knowledge of long-term outcomes of BED and support the planning of evidence-based prevention programs and treatment strategies targeted on the risk factors for the onset and maintenance of BED. Given the high prevalence of adolescents who reported SBED, early detection is needed in order to prevent the evolution and worsening of eating symptoms. Moreover, although it has been underlined that a high prevalence of BED may also be found in male adolescent population, there is a dearth of studies that have specifically focused on the possible effectiveness of intervention programs in boys with BED. Thus, future studies including both female and male adolescents with BED are needed.

\section{Disclosure}

The authors report no conflicts of interest in this work.

\section{References}

1. Striegel-Moore RH, Franko DL. Should binge eating disorder be included in the DSM-V? A critical review of the state of the evidence. Annu Rev Clin Psychol. 2008;4:305-324.

2. Eddy KT, Crosby RD, Keel PK, et al. Empirical identification and validation of eating disorder phenotypes in a multisite clinical sample. J Nerv Ment Dis. 2009;197(1):41-49.

3. Grilo CM, Ivezaj V, White MA. Evaluation of the DSM-5 severity indicator for binge eating disorder in a clinical sample. Behav Res Ther. 2015;71:110-114.

4. American Psychiatric Association. Diagnostic and Statistical Manual of Mental Disorders (DSM-5). Washington, DC: American Psychiatric Association; 2013.

5. Hilbert A, Pike KM, Wilfley DE, Fairburn CG, Dohm FA, StriegelMoore RH. Clarifying boundaries of binge eating disorder and psychiatric comorbidity: a latent structure analysis. Behav Res Ther. 2011;49(3):202-211.

6. Sysko R, Roberto CA, Barnes RD, Grilo CM, Attia E, Walsh BT. Testretest reliability of the proposed DSM-5 eating disorder diagnostic criteria. Psychiatry Res. 2012;196(2):302-308.

7. Kessler RC, Berglund PA, Chiu WT, et al. The prevalence and correlates of binge eating disorder in the World Health Organization World Mental Health Surveys. Biol Psychiatry. 2013;73(9):904-914.

8. Kessler RC, Shahly V, Hudson JI, et al. A comparative analysis of role attainment and impairment in binge-eating disorder and bulimia nervosa: results from the WHO World Mental Health Surveys. Epidemiol Psychiatr Sci. 2014;23(1):27-41.

9. American Psychiatric Association. Diagnostic Criteria from DSM-IVTR. Washington, DC: American Psychiatric Association; 2000.
10. Lee-Winn AE, Reinblatt SP, Mojtabai R, Mendelson T. Gender and racial/ethnic differences in binge eating symptoms in a nationally representative sample of adolescents in the United States. Eat Behav. 2016;22:27-33.

11. Schag K, Schönleber J, Teufel M, Zipfel S, Giel KE. Food-related impulsivity in obesity and Binge Eating Disorder - a systematic review. Obes Rev. 2013;14(6):477-495.

12. Barry DT, Grilo CM, Masheb RM. Gender differences in patients with binge eating disorder. Int J Eat Disord. 2002;31(1):63-70.

13. Masheb RM, Grilo CM. Emotional overeating and its associations with eating disorder psychopathology among overweight patients with binge eating disorder. Int J Eat Disord. 2006;39(2): 141-146.

14. Stein RI, Kenardy J, Wiseman CV, Dounchis JZ, Arnow BA, Wilfley DE. What's driving the binge in binge eating disorder? A prospective examination of precursors and consequences. Int $J$ Eat Disord. 2007;40(3):195-203.

15. Gonzalez A, Kohn M, Clarke S. Eating disorders in adolescents. Aust Fam Physician. 2007;36(8):614.

16. Ágh T, Kovács G, Pawaskar M, Supina D, Inotai A, Vokó Z. Epidemiology, health-related quality of life and economic burden of binge eating disorder: a systematic literature review. Eat Weight Disord. 2015;20(1):1-12.

17. Nicholls D, Barrett E. Eating disorders in children and adolescents. BJPsych Adv. 2015;21(3):206-216.

18. Swanson SA, Crow SJ, Le Grange D, Swendsen J, Merikangas KR. Prevalence and correlates of eating disorders in adolescents: results from the national comorbidity survey replication adolescent supplement. Arch Gen Psychiatry. 2011;68(7):714-723.

19. Paciello M, Fida R, Tramontano C, Cole E, Cerniglia L. Moral dilemma in adolescence: the role of values, prosocial moral reasoning and moral disengagement in helping decision making. Eur J Dev Psychol. 2013;10(2):190-205.

20. Anderson, NK, Nicolay OF. Eating disorders in children and adolescents. Semin Orthod. 2016;22(3):234-237.

21. Cerniglia L, Cimino S, Ballarotto G, Tambelli R. Do parental traumatic experiences have a role in the psychological functioning of early adolescents with binge eating disorder? Eat Weight Disord. 2016;21(4):635-644.

22. Patel P, Wheatcroft R, Park RJ, Stein A. The children of mothers with eating disorders. Clin Child Fam Psychol Rev. 2002;5:1-19.

23. Wu M, Lu LH, Lowes A, et al. Development of superficial white matter and its structural interplay with cortical gray matter in children and adolescents. Hum Brain Mapp. 2014;35(6):2806-2816.

24. Bray S, Krongold M, Cooper C, Lebel C. Synergistic effects of age on patterns of white and gray matter volume across childhood and adolescence. eNeuro. 2015;2(4):3-15.

25. Gondoli DM, Corning AF, Salafia EHB, Bucchianeri MM, Fitzsimmons EE. Heterosocial involvement, peer pressure for thinness, and body dissatisfaction among young adolescent girls. Body Image. 2011;8(2):143-148.

26. Rajagopalan J, Shejwal B. Influence of sociocultural pressures on body image dissatisfaction. Psychol Stud. 2014;59(4):357-364.

27. Cerniglia L, Cimino S, Ballarotto G, et al. Motor vehicle accidents and adolescents: an empirical study on their emotional and behavioural profiles, defense strategies and parental support. Transp Res Part F Traffic Psychol Behav. 2015;35:28-36.

28. Shapiro-Weiss G, Shapiro-Weiss J. Recent advances in child psychiatry: eating disorders common in high school students. Psychiatric Guide. 2001;8:13.

29. Poppe I, Simons A, Glazemakers I, Van West D. Early-onset eating disorders: a review of the literature. Tijdschr Psychiatr. 2015;57(11):805-814.

30. Preti A, de Girolamo G, Vilagut G, et al. The epidemiology of eating disorders in six European countries: results of the ESEMeD-WMH project. J Psychiatr Res. 2009;43(14):1125-1132. 
31. Smink FR, van Hoeken D, Oldehinkel AJ, Hoek HW. Prevalence and severity of DSM-5 eating disorders in a community cohort of adolescents. Int J Eat Disord. 2014;47(6):610-619.

32. Stice E, Marti CN, Rohde P. Prevalence, incidence, impairment, and course of the proposed DSM-5 eating disorder diagnoses in an 8-year prospective community study of young women. J Abnorm Psychol. 2013;122(2):445-457.

33. Croll J, Neumark-Sztainer D, Story M, Ireland M. Prevalence and risk and protective factors related to disordered eating behaviors among adolescents: relationship to gender and ethnicity. J Adolesc Health. 2002;31(2):166-175.

34. Tanofsky-Kraff M, Shomaker LB, Olsen C, et al. A prospective study of pediatric loss of control eating and psychological outcomes. J Abnorm Psychol. 2011;120(1):108.

35. Goldschmidt AB, Wall MM, Loth KA, Bucchianeri MM, NeumarkSztainer D. The course of binge eating from adolescence to young adulthood. Health Psychol. 2014;33(5):457-460.

36. Herpertz-Dahlmann B. Adolescent eating disorders: update on definitions, symptomatology, epidemiology, and comorbidity. Child Adolesc Psychiatr Clin N Am. 2015;24(1):177-196.

37. Tanofsky-Kraff M, Marcus MD, Yanovski SZ, Yanovski JA. Loss of control eating disorder in children age 12 years and younger: proposed research criteria. Eat Behav. 2008;9(3):360-365.

38. Swanson SA, Aloisio KM, Horton NJ, et al. Assessing eating disorder symptoms in adolescence: is there a role for multiple informants? Int $J$ Eat Disord. 2014;47(5):475-482.

39. Sonneville KR, Horton NJ, Micali N, et al. Longitudinal associations between binge eating and overeating and adverse outcomes among adolescents and young adults: does loss of control matter? JAMA Pediatr. 2013;167(2):149-155.

40. Stice E, Marti CN, Shaw H, Jaconis M. An 8-year longitudinal study of the natural history of threshold, subthreshold, and partial eating disorders from a community sample of adolescents. J Abnorm Psychol. 2009;118(3):587-597.

41. Lewinsohn PM, Seeley JR, Moerk KC, Striegel-Moore RH. Gender differences in eating disorder symptoms in young adults. Int $J$ Eat Disord. 2002;32(4):426-440.

42. Striegel-Moore RH, Rosselli F, Perrin N, et al. Gender difference in the prevalence of eating disorder symptoms. Int J Eat Disord. 2009;42(5):471-474.

43. Wilfley DE, Wilson GT, Agras WS. The clinical significance of binge eating disorder. Int J Eat Disord. 2003;34(1):96-106.

44. Whisman MA, Dementyeva A, Baucom DH, Bulik CM. Marital functioning and binge eating disorder in married women. Int J Eat Disord. 2012;45(3):385-389.

45. Green BN, Johnson CD, Adams A. Writing narrative literature reviews for peer-reviewed journals: secrets of the trade. J Chiropr Med. 2006;5:10117.

46. Pan L. Preparing Literature Reviews: Qualitative and Quantitative approaches. 3rd ed. Glendale, CA: Pyrczak Publishing; 2008.

47. Ferrari R. Writing narrative style literature reviews. Medical Writing. 2015;24(4):230-235.

48. Grant MJ, Booth A. A typology of reviews: an analysis of 14 review types and associated methodologies. Health Info Libr J. 2009;26:91-108

49. Egger M, Smith GD, Altman DG. Systematic Reviews in Health Care: Meta-Analysis in Context. London, UK: BMJ Publishing Group; 2001.

50. American Academy of Child and Adolescent Psychiatry. Facts for Families. Washington, DC: American Academy of Child and Adolescent Psychiatry; 2011.

51. Decaluwé V, Braet C. Prevalence of binge-eating disorder in obese children and adolescents seeking weight-loss treatment. Int J Obes Relat Metab Disord. 2003;27(3):404-409.

52. Kjelsås E, Bjørnstrøm C, Götestam KG. Prevalence of eating disorders in female and male adolescents (14-15 years). Eat Behav. 2004;5(1):13-25.
53. Ackard DM, Fulkerson JA, Neumark-Sztainer D. Prevalence and utility of DSM-IV eating disorder diagnostic criteria among youth. Int J Eat Disord. 2007;40(5):409-417.

54. Walsh BT. Report of the DSM-5 Eating Disorders Work Group. Washington, DC: American Psychiatric Association DSM-5 Development; 2009.

55. Fairburn CG, Beglin SJ. Assessment of eating disorders: interview or self-report questionnaire? Int J Eat Disord. 1994;16:363-370.

56. Turner H, Bryant-Waugh R. Eating disorder not otherwise specified (EDNOS): profiles of clients presenting at a community eating disorder service. Eur Eat Disord Rev. 2004;12:18-26.

57. Machado PPP, Goncalves S, Hoek HW. DSM-5 reduces the proportion of EDNOS cases: evidence from community samples. Int J Eat Disord. 2013;46:60-65.

58. Wade TD, Bergin JL, Tiggemann M, Bulik CM, Fairburn CG. Prevalence and long-term course of lifetime eating disorders in an adult Australian twin cohort. Aust N Z J Psychiatry. 2006;40:121-128.

59. Allen KL, Byrne SM, Oddy WH, Crosby RD. DSM-IV-TR and DSM-5 eating disorders in adolescents: prevalence, stability, and psychosocial correlates in a population-based sample of male and female adolescents. J Abnorm Psychol. 2013;122(3):720.

60. Micali N, Solmi F, Horton NJ, et al. Adolescent eating disorders predict psychiatric, high-risk behaviors and weight outcomes in young adulthood. J Am Acad Child Adolesc Psychiatry. 2015;54(8):652-659.

61. Field AE, Sonneville KR, Micali N, et al. Prospective association of common eating disorders and adverse outcomes. Pediatrics. 2012;130(2):e289-e295.

62. Crow SJ, Swanson SA, le Grange D, Feig EH, Merikangas KR. Suicidal behavior in adolescents and adults with bulimia nervosa. Compr Psychiatry. 2014;55(7):1534-1539.

63. Tabler J, Utz RL. The influence of adolescent eating disorders or disordered eating behaviors on socioeconomic achievement in early adulthood. Int J Eat Disord. 2015;48(6):622-632.

64. Micali N, Ploubidis G, De Stavola B, Simonoff E, Treasure J. Frequency and patterns of eating disorder symptoms in early adolescence. J Adolesc Health. 2014;54(5):574-581.

65. Ranzenhofer LM., Columbo KM, Tanofsky-Kraff M, et al. Binge eating and weight-related quality of life in obese adolescents. Nutrients. 2012;4(3):167-180.

66. Forrest LN, Zuromski KL, Dodd DR, Smith AR. Suicidality in adolescents and adults with binge-eating disorder: results from the national comorbidity survey replication and adolescent supplement. Int J Eat Disord. 2017;50(1):40-49.

67. Skinner HH, Haines J, Austin SB, Field AE. A prospective study of overeating, binge eating, and depressive symptoms among adolescent and young adult women. J Adolesc Health. 2012;50(5):478-483.

68. Allen KL, Byrne SM, Oddy WH, Crosby RD. Early onset binge eating and purging eating disorders: course and outcome in a population-based study of adolescents. J Abnorm Child Psychol. 2013;41(7):1083-1096.

69. Wilson GT, Wilfley DE, Agras WS. Psychological treatments of binge eating disorder. Arch Gen Psychiatry. 2010;67(1):94-101.

70. Grilo CM, Masheb RM, Wilson GT. Efficacy of cognitive behavioral therapy and fluoxetine for the treatment of binge eating disorder: a randomized double-blind placebo-controlled comparison. Biol Psychiatry. 2005;57(3):301-309.

71. Wilson GT, Fairburn CC, Agras WS, Walsh BT, Kraemer H. Cognitivebehavioral therapy for bulimia nervosa: time course and mechanisms of change. J Consult Clin Psychol. 2002;70(2):267-274.

72. Agras WS., Fitzsimmons-Craft EE, Wilfley DE. Evolution of cognitive-behavioral therapy for eating disorders. Behav Res Ther. 2017;88:26-36

73. Grilo CM, Masheb RM, Wilson GT, Gueorguieva R, White MA. Cognitive-behavioral therapy, behavioral weight loss, and sequential treatment for obese patients with binge-eating disorder: a randomized controlled trial. J Consult Clin Psychol. 2011;79(5):675-685. 
74. Munsch S, Meyer AH, Biedert E. Efficacy and predictors of long-term treatment success for cognitive-behavioral treatment and behavioral weight-loss-treatment in overweight individuals with binge eating disorder. Behav Res Ther. 2012;50(12):775-785.

75. Rieger E, Van Buren DJ, Bishop M, et al. An eating disorder-specific model of interpersonal psychotherapy (IPT-ED): causal pathways and treatment implications. Clin Psychol Rev. 2010;30(4):400-410.

76. Safer DL, Telch CF, Chen EY. Dialectical Behavior Therapy for Binge Eating and Bulimia. New York: Guilford Press; 2009.

77. Klein AS, Skinner JB, Hawley KM. Targeting binge eating through components of dialectical behavior therapy: preliminary outcomes for individually supported diary card self-monitoring versus group-based DBT. Psychotherapy. 2013;50(4):543-552.

78. Wiser S, Telch CF. Dialectical behavior therapy for binge-eating disorder. J Clin Psychol. 1999;55(6):755-768.

79. DeBar LL, Wilson GT, Yarborough BJ, et al. Cognitive behavioral treatment for recurrent binge eating in adolescent girls: a pilot trial. Cogn Behav Pract. 2013;20(2):147-161.

80. Jones M, Luce KH, Osborne MI, et al. Randomized, controlled trial of an internet-facilitated intervention for reducing binge eating and overweight in adolescents. Pediatrics. 2008;121(3):453-462.

81. Tanofsky-Kraff M, Wilfley DE, Young JF, et al. A pilot study of interpersonal psychotherapy for preventing excess weight gain in adolescent girls at-risk for obesity. Int J Eat Disord. 2010;43(8):701-706.

82. Tanofsky-Kraff M, Shomaker LB, Wilfley DE, et al. Targeted prevention of excess weight gain and eating disorders in high-risk adolescent girls: a randomized controlled trial. Am J Clin Nutr. 2014;100(4):1010-1018.

83. Safer DL, Couturier JL, Lock J. Dialectical behavior therapy modified for adolescent binge eating disorder: a case report. Cogn Behav Pract. 2007;14(2):157-167.

84. Mazzeo SE, Lydecker J, Harney M, et al. Development and preliminary effectiveness of an innovative treatment for binge eating in racially diverse adolescent girls. Eat Behav. 2016;22:199-205.

85. Cooper Z, Fairburn CG. A new cognitive behavioural approach to the treatment of obesity. Behav Res Ther. 2001;39(5):499-511.

86. Nagl M, Jacobi C, Paul M, et al. Prevalence, incidence, and natural course of anorexia and bulimia nervosa among adolescents and young adults. Eur Child Adolesc Psychiatry. 2016;25(8):903-918.

87. Smink FR, Van Hoeken D, Hoek, HW. Epidemiology of eating disorders: incidence, prevalence and mortality rates. Curr Psychiatry Rep. 2012;14(4):406-414.

88. Herpertz-Dahlmann B. Adolescent eating disorders: update on definitions, symptomatology, epidemiology, and comorbidity. Child Adolesc Psychiatr Clin NAm. 2015;24(1):177-196.

89. Reilly JJ, Methven E, McDowell ZC, et al. Health consequences of obesity. Arch Dis Child. 2003;88(9):748-752.

90. Kostro K, Lerman JB, Attia E. The current status of suicide and self-injury in eating disorders: a narrative review. J Eat Disord. 2014;2(1):19.
91. Chesney E, Goodwin GM, Fazel S. Risks of all-cause and suicide mortality in mental disorders: a meta-review. World Psychiatry. 2014;13(2): 153-160.

92. Coughlan H, Tiedt L, Clarke M, et al. Prevalence of DSM-IV mental disorders, deliberate self-harm and suicidal ideation in early adolescence: an Irish population-based study. J Adolesc. 2014;37(1):1-9.

93. NICE Guidelines. Eating Disorder: Recognition and Treatment, Version 1. Commissioned by the National Institute for Health and Care Excellence. London, UK; 2016.

94. Mussell MP, Mitchell JE, Weller CL, Raymond NC, Crow SJ, Crosby $\mathrm{RD}$. Onset of binge eating, dieting, obesity, and mood disorders among subjects seeking treatment for binge eating disorder. Int J Eat Disord. 1995;17(4):395-401.

95. Crow SJ, Peterson CB, Swanson SA, et al. Increased mortality in bulimia nervosa and other eating disorders. Am J Psychiatry. 2009;166(12):1342-1346.

96. Campbell LC, Mill J, Uher R, Schmidt U. Eating disorders, geneenvironment interactions and epigenetics. Neurosci Biobehav Rev. 2011;35(3):784-793.

97. Stice E, Gau JM, Rohde P, Shaw H. Risk factors that predict future onset of each DSM-5 eating disorder: predictive specificity in highrisk adolescent females. J Abnorm Psychol. 2017;126(1):38-51.

98. Lavender JM, Utzinger LM, Cao L, et al. Reciprocal associations between negative affect, binge eating, and purging in the natural environment in women with bulimia nervosa. JAbnorm Psychol. 2016;125(3):381-386.

99. Tambelli R, Cerniglia L, Cimino S, et al. An exploratory study on the influence of psychopathological risk and impulsivity on BMI and perceived quality of life in obese patients. Nutrients. 2017;9(5):E431.

100. Ballarotto G, Porreca A, Erriu M, et al. Does alexithymia have a mediating effect between impulsivity and emotional-behavioural functioning in adolescents with binge eating disorder? Clin Neuropsychiatry.2017;14(4):247-256.

101. Tafà M, Cimino S, Ballarotto G, Bracaglia F, Bottone C, Cerniglia L. Female adolescents with eating disorders, parental psychopathological risk and family functioning. J Child Fam Stud. 2017;26(1):28-39.

102. Cerniglia C, Cimino S, Ballarotto G, Tambelli R. Do parental traumatic experiences have a role in the psychological functioning of early adolescents with binge eating disorder? Eat Weight Disord. 2016;21(4):635-644.

103. Hudson JI, Lalonde JK, Berry JM, et al. Binge-eating disorder as a distinct familial phenotype in obese individuals. Arch Gen Psychiatry. 2006;63(3):313-319.

104. Salvy SJ, De La Haye K, Bowker JC, Hermans RC. Influence of peers and friends on children's and adolescents' eating and activity behaviors. Physiol Behav. 2012;106(3):369-378.

105. Stice E, Presnell K, Spangler D. Risk factors for binge eating onset in adolescent girls: a 2-year prospective investigation. Health Psychol. 2002;21(2):131-138.

106. Tin SP, Ho SY, Mak KH, Wan KL, Lam TH. Lifestyle and socioeconomic correlates of breakfast skipping in Hong Kong. Prev Med. 2011;52(3-4):250-253.
Adolescent Health, Medicine and Therapeutics

Publish your work in this journal

Adolescent Health, Medicine and Therapeutics is an international, peer-reviewed, open access journal focusing on health, pathology, and treatment issues specific to the adolescent age group. All aspects of health maintenance, preventative measures and disease treatment interventions are addressed within the journal and practitioners from all disciplines are
Dovepress

invited to submit their work as well as healthcare researchers and patient support groups. This journal is included in PubMed. The manuscript management system is completely online and includes a very quick and fair peer-review system. Visit http://www.dovepress.com/testimonials. php to read real quotes from published authors. 